\title{
Pain Management Strategies After Orthopaedic Trauma: A Mixed-Methods Study with a View to Optimizing Practices
}

\author{
Sonia Grzelak ${ }^{1,2}$, Mélanie Bérubé (D) ${ }^{1,2}$, Marc-Aurèle Gagnon', Caroline Côté $\mathbb{D}^{1,2}$, Valérie Turcotte ${ }^{3}$, \\ Stéphane Pelet ${ }^{4}$, Étienne Belzile ${ }^{4}$ \\ 'Population Health and Optimal Practices Research Unit (Trauma - Emergency - Critical Care Medicine), Laval University Research Center (Hôpital de \\ l'Enfant-Jésus), Quebec City, QC, Canada; ${ }^{2}$ Faculty of Nursing, Laval University, Quebec City, QC, Canada; ${ }^{3}$ Nursing Department, CIUSSS du Nord-de \\ -l'Île-de-Montréal, Hôpital du Sacré-Coeur de Montréal, Montréal, QC, Canada; ${ }^{4}$ Department of Orthopedic Surgery, CHU de Québec-Université \\ Laval (Hôpital de l'Enfant-Jésus), Quebec City, QC, Canada
}

Correspondence: Sonia Grzelak, Population Health and Optimal Practices Research Unit, Laval University Research Center (Hôpital de l'Enfant-jésus), I40I, $18^{\mathrm{e}}$ rue, Quebec City, QC, GIV IZ4, Canada, Tel + 4 I8 649-0252, ext 66600, Fax + I 4I8-649-5733, Email sonia.grzelak. I@ulaval.ca

Purpose: To examine 1) pain management strategies within the care trajectory of orthopaedic trauma patients and patients' perception of their effectiveness, 2) adverse effects (AEs) associated with pharmacological treatments, particularly opioids and cannabis, and 3) patients' perceptions of strategies that should be applied after an orthopaedic trauma and support that they should obtain from health professionals for their use.

Patients and Methods: This study was conducted with orthopaedic trauma patients in a level 1 trauma center. A convergent mixedmethods design was used. Data on pain experience, pain management strategies used and AEs were collected with self-administered questionnaires at hospital discharge (T1) and at 3 months after injury (T2). Patients' preferences about the pain management strategies used, the required support and AEs were further examined through semi-structured individual interviews at the same time measures. Descriptive statistics and thematic analyses were performed.

Results: Seventy-one patients were recruited and 30 individual interviews were undertaken. Pharmacological pain management strategies used at T1 and T2 were mainly opioids $(95.8 \% ; 20.8 \%)$ and acetaminophen $(91.5 \% ; 37.5 \%)$. The most frequently applied non-pharmacological strategies were sleep (95.6\%) and physical positioning $(89.7 \%)$ at $\mathrm{T} 1$ and massage (46.3\%) and relaxation $(32.5 \%)$ at T2. Findings from quantitative and qualitative analyses highlighted that non-pharmacological strategies, such as comfort, massage, distraction, and physical therapy, were perceived as the most effective by participants. Most common AEs related to opioids were dry mouth $(78.8 \%)$ and fatigue $(66.1 \%)$ at $\mathrm{T} 1$ and insomnia $(30.0 \%)$ and fatigue $(20.0 \%)$ at $\mathrm{T} 2$. Dry mouth $(28.6 \%)$ and drowsiness (14.3\%) were the most reported AEs by patients using recreational cannabis. An important need for information at hospital discharge and for a personalized follow-up was identified by participants during interviews.

Conclusion: Despite its AEs, we found that opioids are still the leading pain management strategy after an orthopaedic trauma and that more efforts are needed to implement non-pharmacological strategies. Cannabis was taken for recreational purposes but patients also used it for pain relief. Support from health professionals is needed to promote the adequate use of these strategies.

Keywords: orthopaedic trauma, pain, pharmacological strategies, non-pharmacological strategies, opioids, cannabis

\section{Introduction}

Traumatic injuries affect a large proportion of the population. In Canada, injuries to various body regions (eg bones and soft tissues, brain, spinal cord, thorax, abdomen) are associated with 3.5 million visits to the emergency rooms and 260,000 hospitalizations per year. ${ }^{1}$ Among patients with traumatic injuries, almost $90 \%$ sustain orthopedic injuries ${ }^{2}$ affecting bones and soft tissues, and these types of injuries are considered to be very painful. Indeed, up to $70 \%$ of orthopaedic trauma patients still report moderate to severe pain at hospital discharge, ${ }^{3,4}$ and almost half of those treated surgically develop chronic pain, ${ }^{4-6}$ one of the highest percentages for any type of surgery. ${ }^{7}$ 
In both the short and the long term, pain leads to physiological changes ${ }^{8-11}$ that considerably impact all aspects of the individual's life. In response to pain, individuals can have emotional and behavioral disorders, ${ }^{11}$ which may lead to disability $^{12}$ and significantly affect the quality of life of those with orthopaedic injuries. ${ }^{10,11,13-15}$ Due to the physical and psychological impacts of pain, about a third of patients are unable to return to work. ${ }^{16-18}$ In addition, inadequately treated pain increases the length of hospital stay, ${ }^{19}$ the total cost of hospitalization ${ }^{20}$ and the frequency of subsequent emergency department visits. ${ }^{21}$ In this regard, orthopaedic injuries are the most expensive non-fatal injuries, ${ }^{22}$ with total direct and indirect costs of up to $\$ 456$ billion per year in the United States ${ }^{23}$ and $\$ 21$ billion in Canada. ${ }^{1}$

In order to alleviate pain from orthopaedic trauma and to address its consequences, a variety of pharmacological and nonpharmacological treatments can be used. Following orthopaedic injuries, guidelines recommend opioid analgesics ${ }^{24-27}$ and non-opioid analgesics (NSAIDs, acetaminophen, gabapentinoids and multimodal analgesia). ${ }^{24-27}$ Recently, there has been a growing interest in cannabis for the management of pain after orthopaedic injuries in countries that have legalized its use, including Canada and the United States. ${ }^{28-32}$ However, the safety profile associated with cannabis use in the context of acute and chronic pain must be taken into consideration and has not been elucidated after a traumatic injury. ${ }^{33}$ Non-pharmacological strategies are typically used as second-line treatment and are composed of physical (eg cold application, ${ }^{24,25,34,35}$ physical exercises, ${ }^{34,35}$ massage ${ }^{24,34,36}$ physical therapy, ${ }^{35}$ acupuncture ${ }^{24}$ and aromatherapy ${ }^{24,25}$ ), cognitive-behavioral (eg coping and relaxation exercises, ${ }^{36-38}$ music $^{24,25,36,38}$ and animal-assisted therapy ${ }^{24,39}$ ) and procedural interventions (eg transcutaneous electrical nerve stimulation (TENS) ${ }^{24-26}$ ).

Considering the high-intensity pain associated with orthopaedic injuries, it is common practice for clinicians to prescribe opioids. ${ }^{40}$ Canada has the second-highest per capita opioid prescribing rate in the world after the United States when measured by defined daily doses, ${ }^{41,42}$ and orthopaedic surgeons are the third-highest prescribers ${ }^{43}$ in the United States. In this regard, the current problems caused by the numerous potential opioid AEs, including the significant risk of addiction, have taken center stage. ${ }^{44}$ Furthermore, several studies have shown that patients taking more opioids after orthopaedic surgery report higher pain intensity and lower satisfaction with pain relief. ${ }^{45-47}$

To ensure that the adverse consequences associated with opioid use after an orthopaedic trauma are minimized, the use of a combination of pharmacological and non-pharmacological strategies is recommended. ${ }^{25}$ Thus, describing the current use of pain management strategies with orthopedic trauma patients and AEs associated with pharmacological treatments, particularly opioids and cannabis, are required to identify areas for improvement. Moreover, in order to select the most beneficial approaches to pain management, a better understanding of patients' needs and preferences is essential. ${ }^{48,49}$

\section{Aim}

In this study, we aimed to examine: 1) pain management strategies used by patients with acute and chronic pain after an orthopaedic trauma and patients' perception of their effectiveness, 2) AEs associated with pharmacological treatments, particularly opioids and cannabis, and 3) patients' perceptions of pain management strategies that should be applied after an orthopaedic trauma and support that they should obtain from health professionals for their use.

\section{Methods}

\section{Design}

A convergent mixed-methods design was used to obtain a more complete understanding of the studied phenomena. ${ }^{50}$ The quantitative section provided a description of the pain experience, the strategies used for pain management and the AEs associated with opioids and cannabis. The qualitative section further examined the patients' preferences about the pain management strategies used, the required support and AEs. The quantitative and qualitative data sets were then merged before interpretation. ${ }^{50}$

\section{Setting}

This study was conducted at a Level 1 trauma center in Québec City, Canada. Data were collected from July 2020 to February 2021 in patients with an orthopaedic trauma, before discharge from the hospital (T1) and 3 months (T2) after their injury. Research Ethics Board (REB) approval (CHU de Québec Laval, No 2021-5295) was granted for this study. 
All study participants gave signed informed consent in accordance with the Declaration of Helsinki and the patient informed consent included publication of anonymized responses.

\section{Eligibility}

Patients were included if they were between 18 and 75 years of age, had been hospitalized for an orthopedic trauma characterized by a combination of severe injury to the musculoskeletal system involving soft tissue and bone ${ }^{51}$ and used opioids during their hospitalization period. Patients who were unable to read and speak French, had cognitive disorders (psychotic or depressive disorder) and presenting with moderate-severe head injury were excluded, considering that these health issues could limit their ability to complete self-administered questionnaires and answer questions during the interviews.

\section{Quantitative Data Collection and Analysis}

Potentially eligible patients were identified by the trauma case manager nurse or the orthopaedic research nurse during hospitalization. The investigator met with the eligible patients in hospital prior to discharge to ask them to take part in the study and obtain informed consent. The first author (SG) collected all the data for this study. Considering its descriptive purpose, no modification of the standard treatments or pain management recommendations were made during the study. Furthermore, none of the data collected was discussed at any time with the treating team in order to influence treatment.

\section{Variables and Measures}

Sociodemographic and clinical data, as well as the analgesics used were collected from patient's medical records. The self-administered questionnaires were completed by patients at two different time points: before hospital discharge (T1) and 3 months after the injury (T2). The Modified Brief Pain Inventory (BPI) was used to measure pain intensity (0: No pain and 10: Most intense pain you can imagine), and to assess the extent of pain interference with patient activities ( 0 : Does not interfere to 10: Completely interferes). ${ }^{52}$ The total score obtained (from 0 to 10) indicates the severity of pain intensity and interference (1-3: mild; 4-6/10: moderate; 7-10/10: severe). ${ }^{53}$ The Neuropathic Pain Symptom Inventory (NPSI) was administered to determine the presence of neuropathic pain. It includes 12 items evaluating five dimensions of neuropathic pain. By adding the 10 descriptors, the total score ranges from 0 to 100, where higher scores represent worse pain. ${ }^{54}$ Mean NPSI total scores of 7, 18, and 34 respectively, indicate 1) low-moderate, (2) moderate, and (3) high pain symptom severity. ${ }^{55}$ The $S F-12 v 2$ questionnaire was applied to assess the quality of life. ${ }^{56}$ It consists of 12 items measuring 8 domains related to the physical and mental health status. ${ }^{57}$ Each domain has a mean score of 50 and standard deviation of 10. The non-pharmacological pain management strategies questionnaire was implemented to assess nonpharmacological strategies used by patients and their perceived level of effectiveness for pain relief. It includes 11 items, each indicating the strategy's level of effectiveness and was developed by a group of experts from the Quebec Pain Registry (Supplemental Digital File 1). ${ }^{58}$ The opioid AEs questionnaire was used to assess the frequency, intensity and level of discomfort of AEs in patients using opioids for pain relief. This tool was adapted from the Opioid-Related Symptom Distress Scale (ORSDS) $)^{59}$ by an expert panel from the Quebec Pain Registry ${ }^{58}$ and the Canadian Neuropathic Pain Database. ${ }^{60}$ Specifically, after listing the most common opioid AEs reported by patients in the Pain Registry, eight AEs were added to the questionnaire (abdominal discomfort, insomnia, swelling, weight gain, blurred vision, decreased libido, hallucinations, nightmares) (Supplemental Digital File 2). Moreover, two AEs were removed (difficulty concentrating, headache) since they were not reported by patients in the Pain Registry. ${ }^{59,61}$ A cannabis component was also assessed with this questionnaire, as the AEs for opioids ${ }^{62,63}$ and cannabis ${ }^{64}$ share many similarities. In order to discriminate between AEs, the patient was first asked to complete the questionnaire according to AEs experienced during opioid use and a second time for AEs during cannabis use. The Opioid Compliance Checklist (OCC) administered to monitor opioid misuse. A positive response to any of the 8 questionnaire items is predictive of opioid misuse. The Cannabis Abuse Screening Test (CAST) was applied to identify cannabis abuse in patients. It includes 6 items indicating habits, behavior, and the effects of cannabis on the user. The total score (from 0 to 24) indicates whether the user is at risk of dependence (0-2 points: low risk; 3-6 points: moderate risk; 7 points and more: high risk). 
Patients did not have to complete the SF-12v2, the OCC and the CAST at T1, but only at T2. In this regard, many items of the SF-12v2 are not adapted for patients who are hospitalized after traumatic injuries. The OCC is designed to assess opioid abuse in chronic pain patients, meaning continued use 3 months or more after injury. Patients could not use cannabis due to hospital regulations, therefore the CAST was administered when the patients returned home. All measurement tools showed adequate psychometric properties in the French language ${ }^{65-69}$ except for the scales on nonpharmacological pain management strategies and opioid AEs that use a simple items listing.

\section{Data Analyses}

Means with standard deviation were calculated for continuous variables. Categorical variables were expressed as counts and percentages (\%). Opioid doses were calculated as oral morphine equivalents per day (MED). ${ }^{70,71}$ Exploratory statistical analyses were also performed to compare the profile of patients still using opioids with those not using opioids at T2. Pearson's Chi-square test was used for the comparison of categorical variables (sex, education, employment status, marital status, injury mechanisms, fracture region, types of intervention, use of benzodiazepine and cannabis), and Student's $t$-test for the comparison of continuous variables (age, number of fractures, number of rib fractures, MED the 3 days prior hospital discharge, pain intensity and interference with activities, neuropathic pain). Statistical analyses were conducted using SPSS (Statistical Package for Social Sciences v27, IBM, Armonk, New York, United States).

\section{Qualitative Data Collection and Analysis}

A total of 30 semi-structured interviews were conducted, which is the number recommended to achieve informational redundancy as per the conclusions of a systematic review on the subject. ${ }^{72}$ Due to Covid restrictions, videoconferencing not being common practice at the beginning of the pandemic, and the absence of email addresses for some participants, patients were contacted by telephone to conduct semi-structured interviews at the three-month follow-up. Patients were considered lost to follow-up after at least five attempts to contact them had failed within 2 weeks to 1 month.

\section{Individual Interview Questionnaire}

The semi-structured interview included a total of 14 questions. The first questions addressed patients' preferred pain management strategies and those considered optimal for pain relief. Then patients were questioned on their expectations regarding the support received to help pain management and AEs associated with opioid and cannabis use. From the 8th question on, participants had two choices. Cannabis users had to answer four questions about advantages and disadvantages, and, for exploratory purposes, the forms used and preferred brands. Non-users had to answer three questions regarding reasons for non-use, interest in medical use and preferred forms for use. Interviews were audio-recorded in a verbatim transcription for later analysis.

\section{Data Analyses}

The chosen qualitative analysis method for this study was a thematic analysis. ${ }^{73,74}$ Using the QDA Miner software (Provalis Research) and according to Braun et al, ${ }^{74}$ the reflective thematic analysis process was carried out in 6 different steps: (1) familiarization with the data, (2) code generation, (3) themes construction, (4) themes reviewing, (5) themes definition and naming phases, (6) production of a report with a final presentation. ${ }^{73}$ Themes organized around several core concepts meeting the objectives of the study were identified and highlighted. ${ }^{73} \mathrm{~A}$ theme is based on a specific question asked during the interview and is supported by data extraction. ${ }^{74}$ The aim of the thematic analysis was to capture a structured and coherent meaning for all the information given by the participants. ${ }^{74} \mathrm{~A}$ free translation of patient quotes, from French to English, was carried out before being validated by a native English speaker.

To ensure the credibility of qualitative data analysis, peer debriefing was carried out by scientists (MB, CC) having a clinical experience with the studied population and in thematic analysis. Transferability was ensured by purposive sampling focusing on particular characteristics, which maximizes the chances of obtaining information that is relevant to the research objectives. ${ }^{75}$ Credibility and transferability were also ensured by triangulation ${ }^{76}$ of the quantitative and qualitative dataset. Furthermore, the ideal coder in thematic analyses is a person with no knowledge of the subject. ${ }^{74}$ Thus, a research assistant with experience in qualitative analysis who did not know the objectives of the study conducted the coding. Code validation was also carried out by S.G and M.B to reach consensus and improve reliability. ${ }^{77}$ To further 
improve reliability and ensure confirmability, peer review ${ }^{75}$ involving verification and validation of the entire data analysis (codes and patient citations) process was carried out by SG and M.B and adjustments were made after discussions between them. Finally, confirmability was ensured both by reviewing the interview transcript documents by the person who conducted the interview (SG), and by methodological triangulation of the data, which was done by $\mathrm{S}$. G. and verified by M.B. ${ }^{75}$

\section{Triangulation of Quantitative and Qualitative Data}

Using data triangulation, the quantitative and qualitative data set were linked. Specifically, descriptive statistics analysis (quantitative technique) and content analysis (qualitative technique) were carried out and the final results were combined at the interpretation stage. ${ }^{78}$

\section{Results \\ Quantitative}

During the study period, among the 107 eligible patients, 71 (66.4\%) agreed to participate, $20(18.7 \%)$ refused, and 16 (14.9\%) were discharged before being approached. From the initial 71 participant sample, $68(95.8 \%)$ completed the questionnaires at T1 and $48(67.6 \%)$ at T2. The attrition rate was $29.4 \%$ and the main reason for loss to follow-up was the inability to contact the patient $(\mathrm{n}=18,26.5 \%)$. One patient $(1.5 \%)$ refused to complete the questionnaire because it was too long and one patient died (1.5\%) before the end of the study.

The characteristics of the patients included in the study are presented in Table 1. The mean age of the sample at T1 was 45.9 years $(\mathrm{SD} \pm 15.4)$, the majority were male $(87.3 \%)$ and in a relationship $(42.6 \%)$. Nearly half of the patients had completed high school (45.6\%) and approximately one third had at least a college diploma (32.4\%). Spine fractures were the most common diagnosis at admission (50.7\%), followed by upper limb and shoulder girdle fractures (45.1\%) and rib fractures $(29.6 \%)$. Patients were generally admitted with approximately $2.9 \pm 2.4$ fractures. Injury mechanisms were mostly motor vehicle collision (38.0\%) and sports injuries (33.8\%). Patients underwent different types of procedures after their traumatic injuries, but surgery was the most common (80.3\%). The average length of hospital stay was $9.2 \pm 8.1$ days after the patients were injured, and all were discharged home. The sociodemographic and clinical characteristics of patients were similar at $\mathrm{T} 2$.

Regarding pain characteristics, almost every patient reported pain at $\mathrm{T} 1$ and $\mathrm{T} 2$ (Table 2). In the last 7 days before questionnaire administration, the mean most intense pain, the mean general pain and the mean neuropathic pain score were moderate to severe at $\mathrm{T} 1(9.3 ; 5.4 ; 35.1)$, and mild to moderate at $\mathrm{T} 2(4.7 ; 2.6 ; 18.4)$. Participants experienced pain interference with many of their living activities, but those with the highest mean scores at $\mathrm{T} 1$ and $\mathrm{T} 2$ were: pain interference with general activities, mobility, work, and recreational activities. For most patients, pain relief was achieved through medication in the last 7 days at $\mathrm{T} 1(72.5 \% \pm 21.6)$, but this score decreased at $\mathrm{T} 2(60.7 \% \pm 33.5)$. According to the SF-12V2 at T2, the mean score for the physical functioning and the role physical domains were $36.5 \pm 36.8$ and 35.7 \pm 32.9 , respectively. These scores were below the mean score of 50 found in the healthy population ${ }^{57}$ while the scores for other domains were comparable to those of the healthy population.

The mean MEDs given in the last 24 hours before discharge was $36.4 \pm 32.6 \mathrm{mg}$ (Table 3). The majority of patients used opioids (ie hydromorphone or morphine) at hospital discharge (95.8\%) and continued use, as prescribed by surgeons or family physicians, was reported for 10 participants (20.8\%) at T2. Statistically significant differences were observed between patients still receiving opioids at T2 compared with those not using them. In this regard, patients still using opioids had experienced more motor vehicle collisions ( $70.0 \%$ vs $31.6 \%)$, had higher pain intensity and pain interference with activities on average ( 4.8 vs $2.2 ; 4.4$ vs 2.2$)$ at $\mathrm{T} 2$, and had more neuropathic pain at T1 and T2 (42.0 vs $31.5 ; 33.0$ vs 15.6). In addition, although the differences were not statistically significant, patients using opioids at $\mathrm{T} 2$ were more often treated surgically (100\% vs $84.2 \%)$, had higher pain intensity and pain interference at discharge on average (6.1 vs $5.1 ; 6.9$ vs 5.9) used more MED the 3 days prior hospital discharge ( $167.0 \mathrm{mg}$ vs $139.9 \mathrm{mg}$ ), used benzodiazepine ( $70.0 \%$ vs $44.7 \%$ ) in a larger proportion during the hospitalization (none were using benzodiazepine at T2), and more had an history of cannabis use $(20.0 \%$ vs $15.8 \%)$. Acetaminophen was used by most participants at $\mathrm{T} 1(91.5 \%)$ and decreased at 
Table I Sociodemographic and Clinical Characteristics of Patients

\begin{tabular}{|c|c|c|}
\hline & $\operatorname{TI}(\mathbf{N}=7 I)$ & $\mathrm{T} 2(\mathbf{N}=48)$ \\
\hline Age, mean (SD) & $45.9(15.42)$ & $47.6(15.1)$ \\
\hline Male, N (\%) & $62(87.3)$ & $4 \mathrm{I}(85.4)$ \\
\hline \multicolumn{3}{|l|}{ Race/Ethnic background, N (\%) } \\
\hline Other North American origin ${ }^{\dagger}$ & $66(97.1)$ & $47(97.9)$ \\
\hline North American indigenous origin ${ }^{\ddagger}$ & $\mathrm{I}(\mathrm{I} .5)$ & $\mathrm{I}(2.1)$ \\
\hline European origin ${ }^{\dagger}$ & $\mathrm{I}(\mathrm{I} .5)$ & 0 \\
\hline \multicolumn{3}{|l|}{ Marital status, $\mathbf{N}(\%)$} \\
\hline In a relationship & $29(42.6)$ & $22(45.8)$ \\
\hline Single & $21(30.9)$ & $12(25.0)$ \\
\hline Married & $15(22.1)$ & $13(27.1)$ \\
\hline Divorced or separated & $3(4.4)$ & I (2.I) \\
\hline \multicolumn{3}{|l|}{ Education, $\mathbf{N}(\%)$} \\
\hline Elementary & $\mathrm{I}(\mathrm{I} .5)$ & $\mathrm{I}(2 . \mathrm{I})$ \\
\hline High school & $31(45.6)$ & $25(52.1)$ \\
\hline College & $23(32.4)$ & $13(27.1)$ \\
\hline University & $13(18.5)$ & $9(18.8)$ \\
\hline \multicolumn{3}{|l|}{ Employment status, $\mathbf{N}(\%)$} \\
\hline Employee & $39(57.4)$ & $28(58.3)$ \\
\hline Self-employed & $10(14.7)$ & $5(10.4)$ \\
\hline Unemployed & $6(8.8)$ & $6(12.5)$ \\
\hline Retired & $5(7.4)$ & $5(10.4)$ \\
\hline Student & $5(7.4)$ & $2(4.2)$ \\
\hline Invalid/long term illness & $2(2.9)$ & $2(4.2)$ \\
\hline On social welfare & $\mathrm{I}(\mathrm{I} .5)$ & 0 \\
\hline TBI, N (\%) & $21(29.6)$ & $13(27.1)$ \\
\hline \multicolumn{3}{|l|}{ Fracture region, $\mathbf{N}(\%)$} \\
\hline Spine & $36(50.7)$ & $23(47.9)$ \\
\hline Upper limb and shoulder girdle & $32(45.1)$ & $22(45.8)$ \\
\hline Thorax & $21(29.6)$ & $18(37.5)$ \\
\hline Pelvis & $16(22.5)$ & $13(27.1)$ \\
\hline Lower limb & $15(21.1)$ & II (22.9) \\
\hline Hip & $13(18.3)$ & II (22.9) \\
\hline \multicolumn{3}{|l|}{ Interventions, N (\%) } \\
\hline Surgery & $57(80.3)$ & $39(81.3)$ \\
\hline Brace/Splint & $24(33.8)$ & $15(3 \mid .3)$ \\
\hline External fixator & $7(9.9)$ & $6(12.5)$ \\
\hline Cast & $7(9.9)$ & $3(6.3)$ \\
\hline None & $10(14.1)$ & $6(12.5)$ \\
\hline \multicolumn{3}{|l|}{ Injury mechanism, N (\%) } \\
\hline Motor vehicle collision & $27(38.0)$ & $19(39.6)$ \\
\hline Sports injury & $24(33.8)$ & $15(31.3)$ \\
\hline Fall & $13(18.3)$ & $9(18.8)$ \\
\hline Work injury & $7(9.9)$ & $5(10.4)$ \\
\hline Number of fractures, mean (SD) ${ }^{\ddagger}$ & $2.9(2.4)$ & $2.9(2.2)$ \\
\hline \multicolumn{3}{|l|}{ Number of rib fractures, $\mathbf{N}(\%)$} \\
\hline 0 & $49(69.0)$ & $30(62.5)$ \\
\hline $1-2$ & $8(11.3)$ & $6(12.5)$ \\
\hline $3-5$ & $8(11.3)$ & $7(14.6)$ \\
\hline $6+$ & $6(8.5)$ & $5(10.4)$ \\
\hline Hospital LOS & $9.2(8.1)$ & $9.0(7.4)$ \\
\hline
\end{tabular}

Notes: ${ }^{\dagger}$ Other North American and European origins are Caucasian. ${ }^{\ddagger}$ Rib fractures excluded from mean considering that several ribs can be fractured in the same patient compared to fractures affecting the limbs, shoulder girdle and pelvis. Abbreviations: TBI, Traumatic Brain Injury; LOS, length of stay. 
Table 2 Patients Pain Characteristics at TI and T2

\begin{tabular}{|c|c|c|}
\hline & TI $(\mathbf{N}=7 I)$ & $\mathrm{T} 2(\mathrm{~N}=48)$ \\
\hline Presence of pain, $\mathrm{N}(\%)$ & $66(93.0)$ & $45(93.8)$ \\
\hline Neuropathic pain score (0-100\%), mean (SD) & $35.1(14.1)$ & $18.4(15.8)$ \\
\hline Most intense pain felt in last 7 days (0-10 NRS), mean (SD) & $9.3(1.1)$ & $4.7(2.8)$ \\
\hline Pain in general felt in last 7 days (0-10 NRS), mean (SD) & $5.4(1.7)$ & $2.6(2.0)$ \\
\hline Percentage of relief obtained through medication in last 7 days, mean (SD) & $72.5(21.6)$ & $60.7(33.5)$ \\
\hline Pain interference with activities (0-10 NRS), mean (SD) General activities & $9.1(1.9)$ & $4.2(3.2)$ \\
\hline Mood & $4.2(3.4)$ & $1.9(3.0)$ \\
\hline Mobility & $8.4(2.3)$ & $3.0(3.1)$ \\
\hline Work & $9.4(1.9)$ & $4.0(3.8)$ \\
\hline Relationships with others & $2.0(3.3)$ & $0.7(2.1)$ \\
\hline Sleep & $6.5(3.1)$ & $2.8(3.5)$ \\
\hline Joy of living & $0.9(2.4)$ & $0.3(1.2)$ \\
\hline Personal care & $6.3(3.4)$ & $0.7(1.5)$ \\
\hline Recreational activities & $8.5(3.2)$ & $5.0(4.2)$ \\
\hline Social activities & $6.8(3.5)$ & $1.6(2.7)$ \\
\hline Mean pain interference with activities & $6.2(1.5)$ & $2.3(1.8)$ \\
\hline
\end{tabular}

Abbreviation: NRS, Numerical Rating Scale.

Table 3 Patient Opioid Use Before Discharge and Co-Analgesic Consumption Three Days Before Discharge and 3 Months After (T2)

\begin{tabular}{|l|r|r|}
\hline & TI (N=7I) & T2 (N=48) \\
\hline MED day before discharge, mean (SD) & \\
Opioid use, N (\%) & $36.4(32.6)$ & - \\
Acetaminophen use, N (\%) & $68(95.8)$ & $10(20.8)$ \\
NSAID, N (\%) & $65(91.5)$ & $18(37.5)$ \\
Pregabalin, N (\%) & $12(16.9)$ & $1(2.1)$ \\
Cyclobenzaprine, N (\%) & $12(16.9)$ & $4(8.3)$ \\
Ketamine/Lidocaine (topical), N (\%) & $3(4.2)$ & $2(4.2)$ \\
Amitriptyline, N (\%) & $2(2.8)$ & 0 \\
Cannabis, N (\%) & $1(1.4)$ & 0 \\
\hline
\end{tabular}

Notes: ${ }^{\dagger}$ MED was not assessed at $\mathrm{T} 2$ as patients did not know the exact frequency and dosage they were taking. PPre-hospital users.

T2 (37.5\%). About a quarter of participants reported recreational cannabis use before $(21.1 \%)$ and after $(25.0 \%)$ their traumatic injuries. On the 10 patients still using opioids at T2, six (60.0\%) were identified as likely to develop opioid misuse. Among 14 participants using cannabis at T2, four (28.6\%) presented a low risk, one (7.1\%) a moderate risk and nine $(64.3 \%)$ a high risk of addiction to cannabis.

As shown in Table 4, the non-pharmacological strategies most frequently applied by healthcare providers or patients at T1 were sleep (95.6\%), physical positioning (89.7\%), comfortable environment (88.2\%), consoling/comforting (76.5\%) and breathing techniques (75.0\%). Conversely, participants used fewer non-pharmacological strategies at T2. Massage (46.3\%), relaxation (32.5\%), physical positioning (24.4\%) and sleep (24.4\%) were the most common. Most of the strategies were perceived as highly effective (ie strategies rated as moderately to very effective by patients) at both time points, with physical positioning $(91.8 \%)$, comfortable environment $(86.7 \%)$, touch $(82.8 \%)$ and massage $(80.0 \%)$ being the most appreciated at T1, and comfortable environment (100\%), massage (94.7\%), sleep (90.0\%) and distraction (77.8\%) at T2.

The majority of participants (87.3\%) had AEs due to opioid use at T1 (Table 5), the most common being dry mouth (78.8\%), fatigue (66.1\%), drowsiness (63.3\%), vertigo (52.1\%), and constipation (39.4\%). At T2, of the 10 participants 
Table 4 Frequency of Non-Pharmacological Strategies and Perceived Effectiveness

\begin{tabular}{|c|c|c|c|c|c|c|}
\hline \multirow[t]{2}{*}{ Strategy } & \multicolumn{3}{|l|}{ TI (N=7I) } & \multicolumn{3}{|l|}{$\mathrm{T} 2(\mathrm{~N}=48)$} \\
\hline & Use N (\%) & $\begin{array}{r}\text { Low Efficacity } \\
\mathbf{N}(\%)^{\dagger}\end{array}$ & $\begin{array}{r}\text { High Efficacity } \\
\mathbf{N}(\%)\end{array}$ & Use $\mathbf{N}(\%)$ & $\begin{array}{r}\text { Low Efficacity } \\
N(\%)\end{array}$ & $\begin{array}{r}\text { High Efficacity } \\
\mathbf{N}(\%)\end{array}$ \\
\hline Sleep & $65(95.6)$ & $17(26.2)$ & $48(73.8)$ & $10(24.4)$ & 0 & $9(90.0)$ \\
\hline Physical positioning & $61(89.7)$ & $5(8.2)$ & $56(91.8)$ & $10(24.4)$ & $3(30.0)$ & $7(70.0)$ \\
\hline Comfortable environment & $60(88.2)$ & $8(13.3)$ & $52(86.7)$ & $7(17.1)$ & 0 & $7(100)$ \\
\hline Consoling/comforting & $52(76.5)$ & $16(30.8)$ & $36(69.2)$ & $3(7.5)$ & $3(100)$ & 0 \\
\hline Breathing techniques & $51(75.0)$ & $13(25.5)$ & $38(74.5)$ & $8(20.0)$ & $3(37.5)$ & $5(62.5)$ \\
\hline Distraction & $43(63.2)$ & $17(39.5)$ & $26(60.5)$ & $9(22.0)$ & I (II.I) & $7(77.8)$ \\
\hline Relaxation & $37(54.4)$ & $10(27.0)$ & $27(73.0)$ & $13(32.5)$ & $4(30.8)$ & $8(61.6)$ \\
\hline Mental imagery & $35(51.5)$ & $8(22.9)$ & $27(77.1)$ & $2(5.0)$ & I (50) & I (50) \\
\hline Touch & $29(42.6)$ & $5(17.2)$ & $24(82.8)$ & $3(7.5)$ & I (33.3) & $2(66.7)$ \\
\hline Massage & $10(14.7)$ & $2(20.0)$ & $8(80.0)$ & $19(46.3)$ & I (5.3) & I8 (94.7) \\
\hline
\end{tabular}

Note: ${ }^{\dagger}$ Efficacy percentages were calculated from the number of participants who used each strategy.

Table 5 Frequency of Side Effects After Opioid and Cannabis Use

\begin{tabular}{|c|c|c|c|}
\hline & TI (N=7I) & T2 $(N=10)$ & $(N=14)$ \\
\hline & Opioid N (\%) & Opioid N (\%) & Cannabis N (\%) \\
\hline Dry mouth & $56(78.8)$ & I $(10.0)$ & $4(28.6)$ \\
\hline Fatigue & $47(66.1)$ & $2(20.0)$ & I (7.I) \\
\hline Drowsiness & $45(63.3)$ & $I(10.0)$ & $2(14.3)$ \\
\hline Vertigo & $37(52.1)$ & $I(10.0)$ & I (7.I) \\
\hline Constipation & $28(39.4)$ & $2(20.0)$ & I (7.I) \\
\hline Confusion & $26(36.6)$ & 0 & 0 \\
\hline Abdominal discomfort & $20(28.1)$ & 0 & 0 \\
\hline Nausea & $18(25.3)$ & 0 & 0 \\
\hline Insomnia & $18(25.3)$ & $3(30.0)$ & 0 \\
\hline Itchiness & 17 (23.9) & 0 & 0 \\
\hline Memory loss & $13(18.3)$ & 0 & 0 \\
\hline Blurred vision & $10(14.0)$ & 0 & 0 \\
\hline Nightmares & $10(14.0)$ & I $(10.0)$ & 0 \\
\hline Swelling & $9(12.6)$ & 0 & 0 \\
\hline Hallucinations & $9(12.6)$ & 0 & 0 \\
\hline Vomiting & $7(9.8)$ & 0 & 0 \\
\hline Decreased urine flow & $7(0.8)$ & 0 & 0 \\
\hline Weight gain & I (I.4) & I (I0.0) & $2(14.3)$ \\
\hline
\end{tabular}

using opioids, $90.0 \%$ reported at least one AE. The most common were insomnia (30.0\%), fatigue (20.0\%), constipation $(20.0 \%)$, dry mouth $(10 \%)$ and drowsiness $(10.0 \%)$. At T2, of the 14 participants who used cannabis, $85.7 \%$ had one or more AEs. Dry mouth (28.6\%) and drowsiness (14.3\%) were the most reported AEs for cannabis users. No cannabis users reported insomnia or nightmares, contrary to opioid users at T2.

\section{Qualitative}

Among the 48 patients contacted at the 3-month follow-up, 30 semi-structured interviews were conducted, beginning with cannabis users and then in the order they were enrolled for patients not using cannabis. ${ }^{72}$ About half of the interviews $(42.2 \%)$ were conducted among cannabis user. The sociodemographic and clinical characteristics of the sample were very similar compared to the T1 general sample, except that more participants were using cannabis. 


\section{Thematic Results}

Core concepts, themes and sub-themes (codes) with sample quotes are presented in Table 6. The themes listed are those that were most frequently discussed in patient interviews. However, all themes, sub-themes and quotes can be consulted in Supplemental Digital File 3.

\section{Concept I: Pain Management}

Theme 1: Preferred method

Patients had a variety of opinions about their preferred method for pain management. They mostly referred to nonpharmacological strategies involving physical interventions (physical therapy, fitness training, home exercises, heat, ice, massage, osteopathy), followed by cognitive interventions (distraction, reflection/acceptance). Secondly, patients reported to appreciate a combination of non-pharmacological and pharmacological strategies (cannabis, non-opioid drugs like acetaminophen, creams and natural methods). Some patients simply waited for the situation to improve over time.

Theme 2: Perceived optimal strategies

Patient answers regarding optimal strategies for pain relief were similar to those for preferred methods. Nonpharmacological strategies, such as physical interventions (rehabilitation exercises, physical therapy, adequate posture, avoiding sudden movements, avoiding strain, massage therapy), were perceived as effective. Cognitive interventions (psychological, breathing/meditation) also emerged as sound solutions. Pharmacological strategies (cannabis, other medication) were not identified as highly useful for pain management. Some individuals however did not have an opinion about the best strategies to manage their pain.

\section{Concept 2: Follow-Up and Support}

Theme 3: Needs \& Expectations

The need for personalized/individualized follow-up was strong and what was provided considered insufficient. Indeed, patients would have liked some help in choosing and using the right medication, a more personalized choice of pain management strategies, better listening by health professionals and access to a resource person. They expressed a feeling of abandonment and a lack of support following discharge. Furthermore, patients expressed their wish for more precise information and more recommendations at discharge. Others also mentioned that they would like to see more attention devoted to monitoring addiction. Finally, some patients did not have any expectations regarding their follow-up and support.

\section{Concept 3: Opioids}

Theme 4: AEs

The majority of patients who experienced AEs referred to physical symptoms, particularly fatigue, drowsiness, constipation, dry mouth, dizziness and nausea. Other uncommon effects, such as excitability, insomnia, dizziness, bitter taste, weight loss, were also reported. Some patients also reported cognitive and behavioral disturbances, mainly confusion, and other less often mentioned issues like memory loss, nightmares, hallucinations and decreased libido. Weaning symptoms such as cold sweats, insomnia, nausea, anxiety and psychological distress were considered one of the worst AEs.

Theme 5: AEs management

Most patients proposed modifications in their treatment to address AEs. Sub-themes included were additional medication (cannabis, laxative), a change in the current treatment (other analgesic), a reduction in dose taken and stopping medication. When it came to modifying treatment, the answers were either undeveloped or short. The majority of participants expressed the desire to continue their opioid treatment after hospital discharge in the presence of pain and few wanted to reduce their opioid consumption to manage AEs during their hospitalization and after discharge. Other patients cited lifestyle changes such as a change in diet and increased water consumption.

\section{Concept 4: Cannabis}

Theme 6: Reasons for use, disadvantages, forms used and preferred brands 
Table 6 Semi-Structured Interview Questions and Themes

\begin{tabular}{|c|c|c|}
\hline $\begin{array}{l}\text { Concept } \\
\text { Framing Questions }\end{array}$ & $\begin{array}{l}\text { Theme } \\
\text { - Sub-Theme }\end{array}$ & Sample Quotes \\
\hline $\begin{array}{l}\text { I.Pain management } \\
\text { "How do you prefer to manage your pain?" } \\
\text { "What strategies do you think would improve } \\
\text { your pain management? " }\end{array}$ & $\begin{array}{l}\text { Preferred method } \\
\text { - None } \\
\text { - Combination of strategies } \\
\text { - Non-pharmacological strategies (physical interventions, cognitive interventions) } \\
\text { - Pharmacological strategies (cannabis, non-opioid medication) } \\
\text { Optimal strategies } \\
\text { - Have no idea } \\
\text { - Non-pharmacological strategies (physical interventions, cognitive interventions) } \\
\text { - Pharmacological strategies (Cannabis, other medication) }\end{array}$ & $\begin{array}{l}\text { "I don't know ... I'm just waiting" P23 } \\
\text { "It (my preference) would still be to stay on the medication and at the same time use massages ... things } \\
\text { like that ..." P67 } \\
\text { "For me, the least pharmacology as possible would be ideal" P5I } \\
\text { "I'm trying a lot of stuff more accurately methods not based on medication to manage the pain, you } \\
\text { know, breathing, baths, exercises" P53 } \\
\text { "As I told you the strategies are more like changing my thoughts, and I will choose to change my } \\
\text { thoughts." P55 } \\
\text { "I do a lot of Labrador tea and CBD oil, it's very effective. [...]. And now I have a wonderful cream } \\
\text { based on lavender-scented hemp oil" P6I } \\
\text { "As I was saying earlier, it's Tylenol, Advil ... that's pretty much what I use mostly for pain." P44 } \\
\text { "I don't know ... that's a good question. But I have no idea" P24 } \\
\text { "It's to be diligent in doing my exercises for my rehabilitation. And, also, the strategy is to go according } \\
\text { to my capacities, you know, not to surpass my capacities but to make a constant progression in this. } \\
\text { Then strategically, it's to set myself realistic short or medium-term objectives for activities or things to } \\
\text { do" P58 } \\
\text { "I believe in breathing and meditation and all of that. I think it could have been a good alternative, in } \\
\text { hospital, in any case, to know how to manage your emotions, that they teach you to breathe too" P53 } \\
\text { "Other medicines but ... I don't know" P3I }\end{array}$ \\
\hline $\begin{array}{l}\text { 2.Follow-up and support } \\
\text { "What are your expectations in terms of follow-up } \\
\text { and support to manage: } \\
\text { a) Pain? } \\
\text { b) Adverse effects?" }\end{array}$ & $\begin{array}{l}\text { Needs \& Expectations } \\
\text { - Non-pharmacological strategies (physical interventions and/or psychological } \\
\text { interventions, offered intervention) } \\
\text { - Personalised follow-up (help for proper choice and use of medication, choice of } \\
\text { analgesic treatment, resource person to be more listened, feeling of abandonment } \\
\text { without resources following discharge) } \\
\text { - More information (more recommendations and more precise information at } \\
\text { discharge) } \\
\text { - Dependency monitoring (more attention given to addiction) } \\
\text { - None }\end{array}$ & $\begin{array}{l}\text { "The centre provides me with the services of physiotherapy of course, but also of a social worker, for } \\
\text { the psychological side, to see how my morale and my condition are going. This is a service that } \\
\text { I appreciated a lot" P58 } \\
\text { "In general, I would like to see other services than pharmacy offered to us. Massage therapy is the first } \\
\text { service that comes to mind that does us good, but it's still expensive when you pay for it out of your } \\
\text { own pocket [...] I would say that if I had had care in this area, once a week, before or after } \\
\text { physiotherapy, it would have helped in an extraordinary way" P5I } \\
\text { "I think a bit more personal follow-up would make a big difference to a lot of people". P44 } \\
\text { "There was no other alternative. That was it. I had no other choice. I would have liked, let's say, to have } \\
\text { been offered and talked to and told that maybe we can try it" P49 } \\
\text { "I would say that it would help. To have someone we can contact" P63 } \\
\text { "Of course when I had a nurse at home to be able to ask questions, it was good"P34 } \\
\text { P44: "On the other hand, when you leave ... you are left to yourself and you left to yourself all alone. } \\
\text { This is it, this is your medicine, your prescription, go home. It ends there [...] That's it and yes, maybe } \\
\text { somebody could have helped me on that side" P44 } \\
\text { "They could still ... you know, they know that you are going to get discharged on such and such a day or } \\
\text { when they find out that you are going to get discharged they could come if sit down with the person to } \\
\text { say: 'we are going to take I5 minutes together and we are going to discuss it' ... but this is not what they } \\
\text { do ..." P44 } \\
\text { "When I talk about addiction, it seems that the doctors didn't care too much" P34 } \\
\text { "I was quite well informed ... I thought about the side effects [...]The follow-up was adequate" P4I }\end{array}$ \\
\hline
\end{tabular}




\begin{tabular}{|c|c|c|}
\hline $\begin{array}{l}\text { 3.Opioids } \\
\text { "Describe your experience of the most } \\
\text { bothersome/constraining adverse effects you } \\
\text { experienced when taking analgesics". } \\
\text { "For the patient taking opioids: Would you like to } \\
\text { change your pain management?" } \\
\text { "What actions have you taken or strategies have } \\
\text { you used to minimize these adverse effects?" } \\
\text { "What strategies do you think would improve the } \\
\text { management of adverse drug reactions? " }\end{array}$ & $\begin{array}{l}\text { Adverse effects } \\
\text { - None } \\
\text { - Physical symptoms (dry mouth, exciting, fatigue, drowsiness, constipation, nausea, } \\
\text { sweating, tremors, dizziness) } \\
\text { - Cognitive and behavioral disorders (decreased libido, hallucinations, nightmares, } \\
\text { confusion, memory loss) } \\
\text { - Weaning } \\
\text { Adverse effects management } \\
\text { - No action taken } \\
\text { - Modification of the treatment (additional medication, change of therapy, dose } \\
\text { reduction, treatment interruption) } \\
\text { - Changes in lifestyle (drink more, diet change) }\end{array}$ & 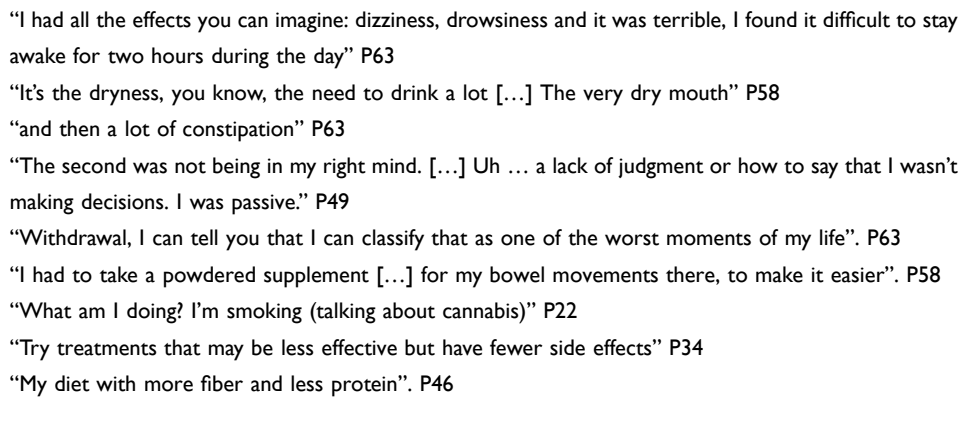 \\
\hline $\begin{array}{l}\text { 4.Cannabis } \\
\text { Do you use cannabis? } \\
\text { If yes, } \\
\text { - For what purpose? } \\
\text { - What are the main advantages and disadvantages? } \\
\text { - Which form(s) do you use it? } \\
\text { - Which brand(s) do you prefer? } \\
\text { If not, } \\
\text { - Why do not you use it? } \\
\text { - Would you be interested in using it for medical } \\
\text { purposes? } \\
\text { - Which form would you be most likely to } \\
\text { consume it? }\end{array}$ & $\begin{array}{l}\text { Reasons for use and adverse effects } \\
\text { - Purpose (analgesic use, recreational use, both use, self-medication) } \\
\text { - Benefits (AEs management, contributes to well-being, pain relief, help to focus) } \\
\text { - Disadvantages (none, difficulties in supplying, AEs, difficulty to use) } \\
\text { - Favorite brands (indifferent, have no idea, choice) } \\
\text { - Used forms (oil, food, smoke) } \\
\text { Reasons for non-use and openness for medical usage } \\
\text { - Reason for non-use (absence of interest, perceived as a drug, mistrust, impacts on } \\
\text { - Mealth, little knowledge on the subject) } \\
\text { - Medical use (interested, uninterested) }\end{array}$ & $\begin{array}{l}\text { "Both. [...] To have fun with my friends and to remove the pain." P24 } \\
\text { "It's that the side effects are very manageable". P34 } \\
\text { "It's definitely a good relaxant. It takes your mind off things". P30 } \\
\text { "It amplifies my happiness (she laughs) and I will laugh a lot ..."P44 } \\
\text { "I wasn't in pain" PI4 } \\
\text { "It helps me to think a bit more correctly too". P23 } \\
\text { "It was expensive" P62 } \\
\text { "I found it stressful to go in there (talking about SQDC)." P62 } \\
\text { "I was no longer able to function when I was using this" P43 } \\
\text { "To have a dry mouth". P3I } \\
\text { "You can't drive while impaired" P35 } \\
\text { "It's that the dosage can be difficult because if you take too much, it's uncomfortable" P34 } \\
\text { "But the brand ... I have no idea." P63 } \\
\text { "There's oil, jujubes, or er ... you know, there are different biscuits, whatever, and I do not have any } \\
\text { trouble with that". P67 } \\
\text { "I smoke it because there is no other way ..." P44 } \\
\text { "I have never used cannabis and I am not interested". P50 } \\
\text { "I just do not trust that. It's a question of trust". P43 } \\
\text { "I'm not attracted to drugs. These are things that scare me." P56 } \\
\text { "Well, yes if it works, because I am prepared to take anything if a specialist tells me that it works". P55 } \\
\text { "I do not know the doctors' opinions on this subject." P55 } \\
\text { "Yes, in oil or spray, I think". P53 } \\
\text { "In pills. [...] I would not want to smell it or taste it but take it like the medicine I am taking now". P49 }\end{array}$ \\
\hline
\end{tabular}


Cannabis was mainly used for recreational purposes. Other participants also used it for its analgesic properties or for both analgesic and recreational purposes. On the one hand, there were many benefits reported with cannabis use, such as a feeling of overall well-being by improving morale, helping with sleep, relaxing, making people laugh, reducing inhibition, stress and boosting spirits. Patients also described cannabis as providing pain relief and helping with concentration and thinking.

On the other hand, patients also reported some disadvantages, mainly cannabis AEs such as dry mouth, drowsiness, memory loss, difficulty speaking, functional impairment and addiction. Patients also spoke about the difficulty of dosing cannabis appropriately, the inability to drive, the prohibition of cannabis in the workplace and the fear of mixing cannabis with other medication. In addition, cannabis cost and legal cannabis shops being stressful to visit were identified as disadvantages. Some patients reported no AEs or disadvantages for cannabis, or if there were, they were easily managed.

Regarding the preferred brand, almost all the patients were indifferent or did not know exactly what they used. The forms used were mostly inhaled cannabis. Oils and cannabis consumption in food were less common.

Theme 7: Reasons for non-use and openness to medical usage

Non-consumers had different reasons for not using cannabis. Most participants reported a lack of interest and perceived cannabis as a drug. Others reported health impacts such as the deleterious effects of inhaled cannabis combustion by-products and possible psychotropic effects. Some patients were suspicious of the substance while others reported a lack of knowledge about this plant. Despite these perceived disadvantages, patients were interested in using cannabis for medical purposes upon recommendation from their physician. The forms of cannabis that non-consumers favored were directly in food, in oil form, in oral sprays and pills.

\section{Discussion}

This study aimed to describe the pain management strategies used by patients and their perceived effectiveness. Furthermore, AEs associated with opioids and cannabis, patients' perception of optimal pain management strategies, and health professional support early after and 3 months after an orthopedic trauma were also analyzed. Most participants were middle-aged males who experienced acute and persistent pain that had a significant impact on their physical functioning. Moreover, a great proportion were at risk of opioid misuse and cannabis dependency. We found that opioids and acetaminophen were the most widely used pharmacological strategies for acute and persistent pain relief. Strategies to improve rest and comfort were the most frequently applied and effective at $\mathrm{T} 1$. The same held true at $\mathrm{T} 2$, but massage and relaxation were more frequently used by participants compared to early after the injury. These findings were corroborated during individual interviews with participants who also expressed their preference for physical strategies such as cryotherapy and physical therapy, as well as cognitive strategies. As for cannabis, most participants used this drug for recreational purposes, but some also believed it contributed to pain relief and improved their mood, sleep and well-being. For those not using cannabis, they expressed a fear of using it given the perceived harmful effects associated with this drug. However, they were willing to consider its use if suggested medically. Participant interviews also highlighted the lack of information and follow-up by health professionals regarding pain management strategies and an important need for a personalized follow-up or a person to contact when questions arise from hospital discharge to 3 months after. Other participants felt that the support they received from health professionals was adequate. A large proportion of participants reported AEs related to opioids and cannabis at both time points and during interviews. Dry mouth, fatigue, drowsiness, and constipation were frequently experienced by participants. Participants using cannabis reported similar AEs to those using opioids. Nonetheless, the interviews also identified cognitive disturbances and decreased physical function as important AEs in those using cannabis.

Our findings are consistent in many areas with those from previous studies. Indeed, a recent retrospective study confirmed that opioids continued to be the gold standard for pain management after an orthopedic trauma despite the current opioid crisis. ${ }^{79}$ Furthermore, the proportion of patients using long-term prescribed opioids, approximately $20 \%$, is similar to that documented in other trauma studies. ${ }^{80,81}$ This is a significant proportion considering that many patients still using opioids at 3 months were identified as being at risk for opioid misuse in our cohort. Furthermore, these patients appeared to have more severe injuries considering that they were more often involved in motor vehicle collisions and required more surgical treatment, which is consistent with the results of studies conducted with cohorts of trauma 
patients. ${ }^{80,82}$ Similarly, they used more opioids at discharge and benzodiazepine during the hospitalization, and had more pain, particularly neuropathic pain, shortly after and at 3 months post-injury. Thus, injury severity, opioid use during hospitalization, anxiety, and neuropathic pain may be factors to consider in identifying patients who require follow-up to prevent opioid misuse and in whom multimodal (pharmacologic and non-pharmacologic) pain management strategies should be more intensively applied after an orthopaedic trauma. In this regard, acetaminophen was predominantly used as a co-analgesic with opioids for the management of postoperative pain in the context of acute orthopedic pain, ${ }^{83}$ which may be explained by its safety profile. However, although integrating NSAIDs early after an orthopaedic trauma was recommended, ${ }^{25}$ they were not often used in our study. This may be due to the fact that pain management protocols do not automatically include NSAIDs and that clinicians may be reluctant to use them considering their effects on bone healing and the risk of bleeding after an injury. ${ }^{84-86}$ As for cannabis, although most participants smoked it for recreational purposes, several also recognized its properties for pain relief and the improvement of associated symptoms. Previous studies have shown a marked interest $(>70 \%)$ in medical cannabis for patients after musculoskeletal injuries and orthopaedic procedures. ${ }^{28,87}$ Heng et al reported that $90 \%$ of patients using cannabis up to 6 months after musculoskeletal injury experienced greater pain relief. ${ }^{28}$ Likewise, a large proportion of patients reported that cannabis could also help improve sleep $(45 \%)^{87}$ and had anxiolytic properties $(62 \%)^{28}$ in studies evaluating patient perception with regard to medical cannabis use. In addition, a recent scoping review indicated that cannabis was effective in $67 \%$ of studies conducted within orthopaedic populations, ${ }^{88}$ but that more high-quality evidence is needed. ${ }^{89,90}$ However, a recent systematic review, showed very small improvement in pain, physical functioning, and sleep quality and no effect on emotional well-being when cannabis was used for the treatment of chronic pain. ${ }^{33}$ Moreover, the opioid-sparing effects of medical cannabis remain unclear. ${ }^{91}$

Regarding non-pharmacological strategies, a descriptive study conducted in the orthopaedic and general surgery departments of a tertiary center reported that nurses applied at least one non-pharmacological strategy on average; physical positioning (97\%), distraction (93\%) and massage (32\%) being the most frequent, similarly to what was used or perceived as effective by participants in our study. ${ }^{92}$ Although less common, these strategies were also deemed advantageous by patients in another study conducted in the orthopaedic, medical and oncology units. ${ }^{93}$ Likewise, a large ( $\mathrm{n}=14767$ ) observational study using data from the world's biggest acute pain post-operative registry (PAIN OUT), revealed that close to half of patients used a non-pharmacological strategy for pain management, with distraction, cold pack, support from the staff or friends/relatives and breathing exercises being the most common. Patients also felt significant pain relief when they used such strategies $(>50 \%)$. Nevertheless, it is important to note that the percentage of pain relief as reported by patients was not greater than for those who did not use non-pharmacological strategies. ${ }^{94}$ Hence, as per the conclusions of a recent systematic review on non-pharmacological strategies after orthopedic surgical procedures, although some (ie relaxation therapy, distraction, guided imagery) may have a potential impact on pain management, more high-quality studies using homogeneous strategy designs and implementation modalities are needed to clarify the role of these strategies. ${ }^{38}$

Furthermore, in agreement with our study, a high prevalence of AEs due to opioids and cannabis were documented in other studies performed within various populations. For example, Gan et al reported that $96 \%$ of patients, early after abdominal surgery, had at least one AE associated with opioids. ${ }^{95}$ Specifically, $82 \%$ presented dizziness, $70 \%$ nausea, 54\% itchiness, 50\% constipation, and 32\% nightmares/hallucinations. ${ }^{95}$ Likewise, according to a Cochrane review, patients with Chronic Non-Cancer Pain (CNCP) who used opioids had a 42\% higher risk of AEs such as constipation, dizziness, drowsiness, fatigue, nausea, pruritus, and vomiting, and a $175 \%$ higher risk of suffering any AE. ${ }^{96}$ However, although most participants in our study reported having at least one opioid-related $\mathrm{AE}$, the rate of each $\mathrm{AE}$ was lower than those reported in another systematic review that analyzed findings from studies conducted in patients with CNCP with a follow-up of up to 24 months. ${ }^{97}$ The fact that patients had been using opioids longer than in our study could explain that AEs were experienced in a larger proportion. Regarding cannabis AEs, there is mixed evidence depending on the cannabinoids used (eg THC vs CBD or a combination of both), however the majority tends to demonstrate that THC use presents more AEs than CBD. ${ }^{98-101}$ Similarly to our findings, somnolence, drowsiness, dizziness and dry mouth are the most common AEs reported for cannabis, no matter the compound used. ${ }^{99,102}$ Nevertheless, according to Parihar et $\mathrm{al}^{99}, \mathrm{CBD}$ generally caused somnolence and gastrointestinal disturbances, whereas THC induced psychoactive effects, 
motor and cognitive impairments. More serious AEs such as psychosomatic symptoms, dysphoric reactions, seizure and cognitive/behavioral effects were found to be less frequent and were documented as being dose and time dependent. ${ }^{100,103}$ However, these findings were based on very low to low level evidence. Hence, more high-quality studies are needed to confirm them. ${ }^{104} \mathrm{CBD}$, does not appear to induce serious AEs, but has been associated with a greater risk of drug interactions. ${ }^{99}$

Finally, weaknesses in the information provided to participants and a lack of personalized follow-up were revealed as important patient concerns over the course of the study. Such issues were also identified in previous studies conducted in patients with pain and who sustained major traumatic injuries. ${ }^{105,106}$ Patients identified several requirements when it comes to improving patient-centered pain management communication. ${ }^{106}$ The most important was to have a shared decision-making process, ${ }^{107}$ based on an assessment of patient needs and preferences and a commitment to address patient pain concerns through multiple avenues of pain management. In this regard, cannabis could be considered as a new therapeutic option for pain management in orthopaedic trauma. ${ }^{108}$ However, patients showing an interest in medical cannabis use should be informed that there is a lack of strong evidence regarding its efficacy and potential AEs, to make an informed decision. Close monitoring of patients, particularly those known to be recreational users, is also required given that several of them were at risk of addiction. Similarly, trauma patients voiced the need for more information on their care plan prior to discharge and for someone to contact for information and advice, showing a need for support to help them manage their pain and medication when they return in the community. ${ }^{105}$ In this regard, individualized support and mutual consensus on therapies to be used are most likely required to increase patient's adherence to pain management treatments and its effectiveness while minimizing AEs. ${ }^{48}$

\section{Strengths and Limitations Strengths}

This is one of the first studies to integrate an evaluation of pain management strategies, patient preferences to manage pain and opioid and cannabis AEs within the orthopaedic trauma population throughout their continuum of care. Furthermore, this mixed design study used rigorous methodology, allowing an in-depth look at these issues. ${ }^{50}$ Hence, findings provide relevant information for health care professionals to improve compliance with recognized guidelines while considering the patient's perspective on preferred pain management strategies and the support they need to use them appropriately.

\section{Limitations}

Some limitations should also be considered. First, the sample predominantly included middle-aged white males, limiting the generalizability of the results. Therefore, there is a need for larger studies including women, older patients and individuals from various backgrounds. Second, it is also possible that patients received a variety of suggestions from professionals during or after their hospitalization about non-pharmacological strategies, which may have influenced their use and perceived effectiveness. However, as discussed above, further studies on these strategies are still needed to confirm their utility in orthopaedics. Third, interviews were only done at 3 months, providing less insight into patient needs shortly after their injury. They were also conducted by telephone and not face-to-face, with a trend towards mostly short answers, sometimes limiting the depth of the information that could be extracted. Finally, qualitative data analyses were not returned to the participants so that they could verify our interpretations and recommend changes. Nonetheless, the credibility of findings was ensured by data analysis and interpretation assessment by two scientists.

\section{Conclusion}

In conclusion, our findings confirm that opioids should be used within reason after an orthopaedic trauma, considering its AEs and the associated risk of misuse. Cannabis is starting to be of interest among other pain relief strategy in countries where its use is legalized but should be considered with caution because it also has AEs. In addition to the pharmacological treatment, several non-pharmacological strategies were used or perceived as effective in the patient continuum of care, including: physical positioning and physical therapy, rest, cryotherapy, massage, relaxation, and distraction. Clear 
information on the use of these different treatments should be provided to patients following their injury. As each patient's pain experience is different, treatment suggestions and follow-up should be adjusted according to individual clinical profile, needs and preferences. Our findings could inform healthcare professionals and health care organizations in the implementation of patient-centered programs aimed at optimizing safe pain management after an orthopaedic trauma.

\section{Acknowledgments}

We thank Christine Rizzo, Nancy Lemieux and Lucie Laplante for their support in identifying potential participants for this study. We would also like to thanks the members of the Quebec Consortium on Adverse Effects of Pain Medications for their thoughts and advice leading to the choice of methods used to conduct this study: (in alphabetical order): Aline Boulanger, Anaïs Lacasse, Anne Hudon, Catherine E. Ferland, Céline Gélinas, David Lussier, David Williamson, Émilie Paul-Savoie, Éric Troncy, Gérard Huni, Gilles Lavigne, Graciela Pineyro, Hélène Beaudry, Jennifer Cogan, Kadija Perreault, Laurent Dupuis, Line Guénette, Lise Dassieu, Louis Gendron, M. Gabrielle Pagé, Manon Choinière, Nabiha Benyamina Douma, Nancy Julien, Philippe Sarret, Pierre Rainville, Simon Décary, Sylvie Lafrenaye, Sylvie Lemay, and Yoram Shir.

\section{Funding}

This research was supported by the Quebec Network on Nursing Intervention Research (no reference number) and the Quebec Pain Research Network (no reference number).

\section{Disclosure}

Dr Stéphane Pelet reports grants from CIHR, grants from MSSS, grants from CRSH, outside the submitted work. Dr Etienne Belzile reports grants from CIHR, grants, personal fees from Stryker, grants, personal fees from DePuy Synthèse, grants, personal fees from BodyCad, personal fees from Pendopharm, personal fees from Conmed, outside the submitted work. Mélanie Bérubé received research salary award from FRQS and SPOR - Quebec. The authors report no other conflicts of interest in this work.

\section{References}

1. Parachute. The cost of injury in Canada; 2015. Available from: https://parachute.ca/wp-content/uploads/2019/06/Cost_of_Injury-2015.pdf. Accessed July 30, 2021.

2. American College of Surgeons Committee on Trauma Leadership. National trauma databank 2016 annual report; 2016. Available from: https:// www.facs.org/ /media/files/quality\%20programs/trauma/ntdb/ntdb\%20annual\%20report\%202016.ashx. Accessed July 25, 2021.

3. Archer KR, Castillo RC, Wegener ST, Abraham CM, Obremskey WT. Pain and satisfaction in hospitalized trauma patients: the importance of self-efficacy and psychological distress. J Trauma Acute Care Surg. 2012;72(4):1068-1077. doi:10.1097/TA.0b013e3182452df5

4. Williamson OD, Epi GD, Gabbe BJ, et al. Predictors of moderate or severe pain 6 months after orthopaedic injury: a prospective cohort study. J Orthop Trauma. 2009;23(2):139-144. doi:10.1097/BOT.0b013e3181962e29

5. Fuzier R, Rousset J, Bataille B, Salces-y-Nedeo A, Magues JP. One half of patients reports persistent pain three months after orthopaedic surgery. Anaesth Crit Care Pain Med. 2015;34(3):159-164. doi:10.1016/j.accpm.2014.09.006

6. Berube M. Evidence-based strategies for the prevention of chronic post-intensive care and acute care-related pain. AACN Adv Crit Care. 2019;30(4):320-334. doi:10.4037/aacnacc2019285

7. Simanski CJ, Althaus A, Hoederath S, et al. Incidence of chronic postsurgical pain (CPSP) after general surgery. Pain Med. 2014;15 (7):1222-1229. doi:10.1111/pme.12434

8. Desborough JP. The stress response to trauma and surgery. Br J Anaesth. 2000;85(1):109-117. doi:10.1093/bja/85.1.109

9. Eisenach JC. Treating and preventing chronic pain: a view from the spinal cord-Bonica Lecture, ASRA annual meeting, 2005. Reg Anesth Pain Med. 2006;31(2):146-151. doi:10.1016/j.rapm.2005.11.011

10. Kehlet H, Jensen TS, Woolf CJ. Persistent postsurgical pain: risk factors and prevention. Lancet. 2006;367(9522):1618-1625. doi:10.1016/ S0140-6736(06)68700-X

11. Joshi GP, Ogunnaike BO. Consequences of inadequate postoperative pain relief and chronic persistent postoperative pain. Anesthesiol Clin North Am. 2005;23(1):21-36. doi:10.1016/j.atc.2004.11.013

12. Young Casey C, Greenberg MA, Nicassio PM, Harpin RE, Hubbard D. Transition from acute to chronic pain and disability: a model including cognitive, affective, and trauma factors. Pain. 2008;134(1-2):69-79. doi:10.1016/j.pain.2007.03.032

13. Phillips CJ. Economic burden of chronic pain. Expert Rev Pharmacoecon Outcomes Res. 2006;6(5):591-601. doi:10.1586/14737167.6.5.591

14. Stewart WF, Ricci JA, Chee E, Morganstein D, Lipton R. Lost productive time and cost due to common pain conditions in the US workforce. JAMA. 2003;290(18):2443-2454. doi:10.1001/jama.290.18.2443 
15. van Leeuwen MT, Blyth FM, March LM, Nicholas MK, Cousins MJ. Chronic pain and reduced work effectiveness: the hidden cost to Australian employers. Eur J Pain. 2006;10(2):161-166. doi:10.1016/j.ejpain.2005.02.007

16. Clay FJ, Newstead SV, McClure RJ. A systematic review of early prognostic factors for return to work following acute orthopaedic trauma. Injury. 2010;41(8):787-803. doi:10.1016/j.injury.2010.04.005

17. Sutherland AG, Alexander DA, Hutchison JD. Recovery after musculoskeletal trauma in men and women. $J$ Trauma. 2005;59(1):213-216. doi:10.1097/01.TA.0000162730.86809.61

18. O'Hara NN, Isaac M, Slobogean GP, Klazinga NS. The socioeconomic impact of orthopaedic trauma: a systematic review and meta-analysis. PLoS One. 2020;15(1):e0227907. doi:10.1371/journal.pone.0227907

19. Morrison RS, Magaziner J, McLaughlin MA, et al. The impact of post-operative pain on outcomes following hip fracture. Pain. $2003 ; 103$ (3):303-311. doi:10.1016/S0304-3959(02)00458-X

20. Hunt KJ, Higgins TF, Carlston CV, Swenson JR, McEachern JE, Beals TC. Continuous peripheral nerve blockade as postoperative analgesia for open treatment of calcaneal fractures. J Orthop Trauma. 2010;24(3):148-155. doi:10.1097/BOT.0b013e3181bfc9f7

21. Menendez ME, Ring D. Emergency department visits after hand surgery are common and usually related to pain or wound issues. Clin Orthop Relat Res. 2016;474(2):551-556. doi:10.1007/s11999-015-4489-1

22. Miller TR, Lestina DC. Patterns in US medical expenditures and utilization for injury, 1987. Am J Public Health. 1996;86(1):89-93. doi:10.2105/AJPH.86.1.89

23. Center for Disease Control and Prevention, National Center for Injury Prevention and Control. Cost of injury care; 2017. Available from: https:// www.cdc.gov/injury/wisqars/cost/index.html. Accessed July 15, 2021.

24. American College of Surgeons. - Committee on Trauma. ACS trauma quality programs. Best practices guidelines for acute pain management in trauma patients; 2020. Available from: https://www.doh.wa.gov/Portals/1/Documents/2900/AcutePainMgmtTraumaPatients.pdf. Accessed July 30, 2021.

25. Hsu JR, Mir H, Wally MK, Seymour RB; Orthopaedic Trauma Association Musculoskeletal Pain Task Force. Clinical practice guidelines for pain management in acute musculoskeletal injury. J Orthop Trauma. 2019;33(5):e158-e182. doi:10.1097/BOT.0000000000001430

26. Chou R, Gordon DB, de Leon-casasola OA, et al. Management of postoperative pain: a clinical practice guideline from the American Pain Society, the American Society of Regional Anesthesia and Pain Medicine, and the American Society of Anesthesiologists' Committee on Regional Anesthesia, Executive Committee, and Administrative Council. J Pain. 2016;17(2):131-157. doi:10.1016/j.jpain.2015.12.008

27. Neścior-Piech M, Orzeł A, Piech P, Janeczko D, Miziak P. Perioperative pain management of orthopaedic patients based on new guidelines and literature review. J Educ Health Sport. 2019;9(9):1195-1207.

28. Heng M, McTague MF, Lucas RC, Harris MB, Vrahas MS, Weaver MJ. Patient perceptions of the use of medical marijuana in the treatment of pain after musculoskeletal trauma: a survey of patients at 2 trauma centers in Massachusetts. J Orthop Trauma. 2018;32(1):e25-e30. doi:10.1097/BOT.0000000000001002

29. Madden K, George A, van der Hoek NJ, Borim FM, Mammen G, Bhandari M. Cannabis for pain in orthopedics: a systematic review focusing on study methodology. Can J Surg. 2019;62(6):369-380. doi:10.1503/cjs.001018

30. Bhashyam AR, Heng M, Harris MB, Vrahas MS, Weaver MJ. Self-reported marijuana use is associated with increased use of prescription opioids following traumatic musculoskeletal injury. J Bone Joint Surg Am. 2018;100(24):2095-2102. doi:10.2106/JBJS.17.01400

31. Salottolo K, Peck L, Tanner IA, et al. The grass is not always greener: a multi-institutional pilot study of marijuana use and acute pain management following traumatic injury. Patient Saf Surg. 2018;12:16. doi:10.1186/s13037-018-0163-3

32. Morrow M. The effects of cannabinoid use on acute orthopaedic pain: a review of the current literature. J Bone Joint Surg. $2020 ; 8(2)$ :e0006.

33. Wang L, Hong PJ, May C, et al. Medical cannabis or cannabinoids for chronic non-cancer and cancer related pain: a systematic review and meta-analysis of randomised clinical trials. BMJ. 2021;374:n1034. doi:10.1136/bmj.n1034

34. Ekman EF, Koman LA. Acute pain following musculoskeletal injuries and orthopaedic surgery: mechanisms and management. Instr Course Lect. 2005;54:21-33.

35. Rosenbloom BN, Katz J, Chin KYW, et al. Predicting pain outcomes after traumatic musculoskeletal injury. Pain. 2016;157(8):1733-1743. doi:10.1097/j.pain.0000000000000580

36. Büyüky1lmaz F. Non- pharmacological intervention in orthopedic pain: a systematic review. Int J Caring Sci. 2014;7(3):718-726.

37. Jadon A. Pain managment in orthopedic patient. In: Essential Orthopedics: Principles \& Practice. JaypeeDigital; 2016:1849-1863.

38. Fan M, Chen Z. A systematic review of non-pharmacological interventions used for pain relief after orthopedic surgical procedures. Exp Ther Med. 2020;20(5):36. doi:10.3892/etm.2020.9163

39. Torani R, Byrd D. Pain management for orthopedic patients; closing the gap. Nurs Clin North Am. 2020;55(2):225-238. doi:10.1016/j. cnur.2020.02.004

40. Busse JW, Craigie S, Juurlink DN, et al. Guideline for opioid therapy and chronic noncancer pain. CMAJ. 2017;189(18):E659-E666. doi:10.1503/cmaj.170363

41. International Narcotics Control Board. Narcotic drugs: estimated world requirements for 2004, statistics for 2002. 2004.

42. International Narcotics Control Board. Availability of internationally controlled drugs: ensuring adequate access for medical and scientific purposes. 2016.

43. Boezaart AP, Nin OC, Parvataneni HK. Acute and perioperative pain medicine and orthopedic surgery: a crucial partnership. Techniq Orthopaed. 2017;32(4):199. doi:10.1097/BTO.0000000000000264

44. Salsitz EA. Chronic pain, chronic opioid addiction: a complex nexus. J Med Toxicol. 2016;12(1):54-57. doi:10.1007/s13181-015-0521-9

45. Nota SP, Spit SA, Voskuyl T, Bot AG, Hageman MG, Ring D. Opioid use, satisfaction, and pain intensity after orthopedic surgery. Psychosomatics. 2015;56(5):479-485. doi:10.1016/j.psym.2014.09.003

46. Koehler RM, Okoroafor UC, Cannada LK. A systematic review of opioid use after extremity trauma in orthopedic surgery. Injury. 2018;49 (6):1003-1007. doi:10.1016/j.injury.2018.04.003

47. Bot AG, Bekkers S, Arnstein PM, Smith RM, Ring D. Opioid use after fracture surgery correlates with pain intensity and satisfaction with pain relief. Clin Orthop Relat Res. 2014;472(8):2542-2549. doi:10.1007/s11999-014-3660-4

48. Crooks L. Assessing pain and the joint commission pain standards. Top Emerg Med. 2002;24:1-9. 
49. Schmier JK, Palmer CS, Flood EM, Gourlay G. Utility assessments of opioid treatment for chronic pain. Pain Med. 2002;3(3):218-230. doi:10.1046/j.1526-4637.2002.02045.x

50. Creswell JW, Creswell JD. Research Design: Qualitative, Quantitative, and Mixed Methods Approaches. 5th ed. Los Angeles: Sage; 2018.

51. Orthopedic Trauma. What constitutes orthopedic trauma; 2018. Available from: https://www.oaidocs.com/2018/04/13/constitutes-orthopedictrauma/. Accessed May 30, 2021.

52. Cleeland C. The brief pain inventory user guide; 2009. Available from: https://www.mdanderson.org/documents/Departments-and-Divisions /Symptom-Research/BPI_UserGuide.pdf. Accessed June 15, 2021.

53. Gerbershagen HJ, Rothaug J, Kalkman CJ, Meissner W. Determination of moderate-to-severe postoperative pain on the numeric rating scale: a cut-off point analysis applying four different methods. Br J Anaesth. 2011;107(4):619-626. doi:10.1093/bja/aer195

54. Bouhassira D, Attal N, Fermanian J, et al. Development and validation of the Neuropathic Pain Symptom Inventory. Pain. 2004;108 (3):248-257. doi:10.1016/j.pain.2003.12.024

55. Wong ML, Fleming L, Robayo LE, Widerstrom-Noga E. Utility of the Neuropathic Pain Symptom Inventory in people with spinal cord injury. Spinal Cord. 2020;58(1):35-42. doi:10.1038/s41393-019-0338-5

56. Dworkin RH, Turk DC, Farrar JT, et al. Core outcome measures for chronic pain clinical trials: IMMPACT recommendations. Pain. 2005;113 (1-2):9-19. doi:10.1016/j.pain.2004.09.012

57. Ware J, Kosinski M, Keller S. SF-12: How to Score the SF-12 Physical and Mental Health Summary Scales. 2nd ed. Boston: The Health Institute, New England Medical Center; 1995.

58. Choiniere M, Ware MA, Page MG, et al. Development and implementation of a registry of patients attending multidisciplinary pain treatment clinics: the Quebec pain registry. Pain Res Manag. 2017;2017:8123812. doi:10.1155/2017/8123812

59. Apfelbaum JL, Gan TJ, Zhao S, Hanna DB, Chen C. Reliability and validity of the perioperative opioid-related symptom distress scale. Anesth Analg. 2004;99(3):699-709. doi:10.1213/01.ANE.0000133143.60584.38

60. Moulin DE, Clark AJ, Gordon A, et al. Long-term outcome of the management of chronic neuropathic pain: a prospective observational study. $J$ Pain. 2015;16(9):852-861. doi:10.1016/j.jpain.2015.05.011

61. Yadeau JT, Liu SS, Rade MC, Marcello D, Liguori GA. Performance characteristics and validation of the Opioid-Related Symptom Distress Scale for evaluation of analgesic side effects after orthopedic surgery. Anesth Analg. 2011;113(2):369-377. doi:10.1213/ ANE.0b013e31821ae3f7

62. Benyamin R, Trescot AM, Datta S, et al. Opioid complications and side effects. Pain Physician. 2008;11(2 Suppl):S105-120. doi:10.36076/ ppj.2008/11/S105

63. Gouvernement du Canada Cannabis use, effects and risks - health effects of cannabis; 2018. Available from: https://www.canada.ca/en/healthcanada/services/drugs-medication/cannabis/health-effects/effects.html. Accessed. June 15, 2021.

64. Patel J, Marwaha R. Cannabis use disorder. In: StatPearls. Treasure Island: StarPearls Publishing; 2021.

65. Poundja J, Fikretoglu D, Guay S, Brunet A. Validation of the French version of the brief pain inventory in Canadian veterans suffering from traumatic stress. J Pain Symptom Manage. 2007;33(6):720-726. doi:10.1016/j.jpainsymman.2006.09.031

66. Poirier C, Martel MO, Berube M, et al. French-Canadian translation of a self-report questionnaire to monitor opioid therapy for chronic pain: the Opioid Compliance Checklist (OCC-FC). Can J Pain. 2020;4(1):59-66. doi:10.1080/24740527.2020.1724777

67. Spilka S, Janssen E, Legleye S. Available from: Detection of Problematic Cannabis Users: The Cannabis Abuse Screening Test (CAST). French Observatory of Drugs and Addictions (OFDT); 2013. https://www.ofdt.fr/BDD/publications/docs/eisxsst9.pdf. Accessed August 4, 2021.

68. Gandek B, Ware JE, Aaronson NK, et al. Cross-validation of item selection and scoring for the SF-12 Health Survey in nine countries: results from the IQOLA project. International Quality of Life Assessment. J Clin Epidemiol. 1998;51(11):1171-1178. doi:10.1016/S0895-4356(98) 00109-7

69. ePROVIDE. Online support for clinical outcome assessments, Neuropathic Pain Symptom Inventory (NPSI). Available from: https://eprovide. mapi-trust.org/instruments/neuropathic-pain-symptom-inventory. Accessed May 24, 2020.

70. Gilson AM, Maurer MA, Ryan KM, Rathouz PJ, Cleary JF. Using a morphine equivalence metric to quantify opioid consumption: examining the capacity to provide effective treatment of debilitating pain at the global, regional, and country levels. J Pain Symptom Manage. 2013;45 (4):681-700. doi:10.1016/j.jpainsymman.2012.03.011

71. Svendsen K, Borchgrevink P, Fredheim O, Hamunen K, Mellbye A, Dale O. Choosing the unit of measurement counts: the use of oral morphine equivalents in studies of opioid consumption is a useful addition to defined daily doses. Palliat Med. 2011;25(7):725-732. doi:10.1177/ 0269216311398300

72. Vasileiou K, Barnett J, Thorpe S, Young T. Characterising and justifying sample size sufficiency in interview-based studies: systematic analysis of qualitative health research over a 15-year period. BMC Med Res Methodol. 2018;18(1):148. doi:10.1186/s12874-018-0594-7

73. Braun V, Clarke V. Using thematic analysis in psychology. Qual Res Psychol. 2006;3(2):77-101. doi:10.1191/1478088706qp063oa

74. Braun V, Clarke V, Hayfield N, Terry G. Thematic analysis. In: Liamputtong P, editor. Handbook of Research Methods in Health Social Sciences. Penrith: Springer Singapore; 2018.

75. Anney VN. Ensuring the quality of the findings of qualitative research: looking at trustworthiness criteria. JETERAPS. 2015;5(2):272-281.

76. Denzin NK, Lincoln YS. The SAGE Handbook of Qualitative Research. Thousands Oaks: SAGE Publications; 2005.

77. Boyatzis R. Transforming Qualitative Information: Thematic Analysis and Code Development. Thousand Oaks: Sage; 1998.

78. Sandelowski M. Combining qualitative and quantitative sampling, data collection, and analysis techniques in mixed-method studies. Res Nurs Health. 2000;23(3):246-255. doi:10.1002/1098-240X(200006)23:3<246::AID-NUR9>3.0.CO;2-H

79. Ruder J, Wally MK, Oliverio M, Seymour RB, Hsu JR, Group P. Patterns of opioid prescribing for an orthopaedic trauma population. J Orthop Trauma. 2017;31(6):e179-e185. doi:10.1097/BOT.0000000000000834

80. Mohamadi A, Chan JJ, Lian J, et al. Risk factors and pooled rate of prolonged opioid use following trauma or surgery: a systematic review and meta-(regression) analysis. J Bone Joint Surg Am. 2018;100(15):1332-1340. doi:10.2106/JBJS.17.01239

81. Page MG, Kudrina I, Zomahoun HTV, et al. A systematic review of the relative frequency and risk factors for prolonged opioid prescription following surgery and trauma among adults. Ann Surg. 2020;271(5):845-854. doi:10.1097/SLA.0000000000003403

82. Lapidus JB, Santosa KB, Skolnick GB, et al. Opioid prescribing and use patterns in postsurgical facial trauma patients. Plast Reconstr Surg. 2020;145(3):780-789. doi:10.1097/PRS.0000000000006588 
83. Parvizi J, Bloomfield MR. Multimodal pain management in orthopedics: implications for joint arthroplasty surgery. Orthopedics. 2013;36(2 Suppl):7-14. doi:10.3928/01477447-20130122-51

84. Usman Ali M, Usman M, Patel K. Effects of NSAID use on bone healing: a meta-analysis of retrospective case-control and cohort studies within clinical settings. Sage J. 2019;22(2):94-111.

85. Wheatley BM, Nappo KE, Christensen DL, Holman AM, Brooks DI, Potter BK. Effect of NSAIDs on bone healing rates: a meta-analysis. $J$ Am Acad Orthop Surg. 2019;27(7):e330-e336. doi:10.5435/JAAOS-D-17-00727

86. Zhao-Fleming $\mathrm{H}$, Hand $\mathrm{A}$, Zhang $\mathrm{K}$, et al. Effect of non-steroidal anti-inflammatory drugs on post-surgical complications against the backdrop of the opioid crisis. Burns Trauma. 2018;6:25. doi:10.1186/s41038-018-0128-x

87. Jennings JM, Johnson RM, Brady AC, Dennis DA. Patient perception regarding potential effectiveness of cannabis for pain management. J Arthroplasty. 2020;35(12):3524-3527. doi:10.1016/j.arth.2020.06.051

88. Madden K, van der Hoek N, Chona S, et al. Cannabinoids in the management of musculoskeletal pain: a critical review of the evidence. JBJS Rev. 2018;6(5):e7. doi:10.2106/JBJS.RVW.17.00153

89. Kleeman-Forsthuber LT, Dennis DA, Jennings JM. Medicinal cannabis in orthopaedic practice. J Am Acad Orthop Surg. $2020 ; 28(7): 268-277$. doi:10.5435/JAAOS-D-19-00438

90. Vivace BJ, Sanders AN, Glassman SD, Carreon LY, Laratta JL, Gum JL. Cannabinoids and orthopedic surgery: a systematic review of therapeutic studies. J Orthop Surg Res. 2021;16(1):57. doi:10.1186/s13018-021-02205-y

91. Noori A, Miroshnychenko A, Shergill Y, et al. Opioid-sparing effects of medical cannabis or cannabinoids for chronic pain: a systematic review and meta-analysis of randomised and observational studies. BMJ Open. 2021;11(7):e047717. doi:10.1136/bmjopen-2020-047717

92. Lewis MJM, Kohtz C, Emmerling S, Fisher M, McGarvey J. Pain control and nonpharmacologic interventions. Nursing. 2018;48(9):65-68. doi:10.1097/01.NURSE.0000544231.59222.ab

93. Tasso K, Behar-Horenstein LS. Patients' perceptions of pain management and use of coping strategies. Hosp Top. 2004;82(4):10-19. doi:10.3200/HTPS.82.4.10-19

94. Komann M, Weinmann C, Schwenkglenks M, Meissner W. Non-pharmacological methods and post-operative pain relief: an observational study. Anesth Pain Med. 2019;9(2):e84674. doi:10.5812/aapm.84674

95. Gan TJ, Lubarsky DA, Flood EM, et al. Patient preferences for acute pain treatment. Br J Anaesth. 2004;92(5):681-688. doi:10.1093/bja/ aeh123

96. Els C, Jackson TD, Kunyk D, et al. Adverse events associated with medium- and long-term use of opioids for chronic non-cancer pain: an overview of Cochrane reviews. Cochrane Database Syst Rev. 2017;10:CD012509. doi:10.1002/14651858.CD012509.pub2

97. Kalso E, Edwards JE, Moore AR, McQuay HJ. Opioids in chronic non-cancer pain: systematic review of efficacy and safety. Pain. 2004;112 (3):372-380. doi:10.1016/j.pain.2004.09.019

98. Mohiuddin M, Blyth FM, Degenhardt L, et al. General risks of harm with cannabinoids, cannabis, and cannabis-based medicine possibly relevant to patients receiving these for pain management: an overview of systematic reviews. Pain. 2021;162(Suppl 1):S80-S96. doi:10.1097/j. pain.0000000000002000

99. Parihar V, MacKillop J, Busse JW. Cannabidiol: A Review of Its Safety for Human Consumption. Hamilton: Michael G.DeGroote Centre for Medicinal Cannabis Research; 2019.

100. Zeraatkar D, Cooper MA, Agarwal A, et al. Long-term and serious harms of medical cannabis and cannabinoids for chronic pain: a systematic review of non-randomized studies. medRxiv. 2021. doi:10.1101/2021.05.27.21257921

101. Busse JW, Vankrunkelsven P, Zeng L, et al. Medical cannabis or cannabinoids for chronic pain: a clinical practice guideline. BMJ. 2021;374: n2040. doi:10.1136/bmj.n2040

102. Pratt M, Stevens A, Thuku M, et al. Benefits and harms of medical cannabis: a scoping review of systematic reviews. Syst Rev. 2019;8(1):320. doi:10.1186/s13643-019-1243-x

103. Sideli L, Trotta G, Spinazzola E, La Cascia C, Di Forti M. Adverse effects of heavy cannabis use: even plants can harm the brain. Pain. 2021;162(Suppl 1):S97-S104. doi:10.1097/j.pain.0000000000001963

104. Guyatt GH, Oxman AD, Vist GE, et al. GRADE: an emerging consensus on rating quality of evidence and strength of recommendations. $B M J$. 2008;336(7650):924-926. doi:10.1136/bmj.39489.470347.AD

105. Braaf S, Ameratunga S, Nunn A, et al. Patient-identified information and communication needs in the context of major trauma. BMC Health Serv Res. 2018;18(1):163. doi:10.1186/s12913-018-2971-7

106. Haverfield MC, Giannitrapani K, Timko C, Lorenz K. Patient-centered pain management communication from the patient perspective. J Gen Intern Med. 2018;33(8):1374-1380. doi:10.1007/s11606-018-4490-y

107. Fu Y, Yu G, McNichol E, Marczewski K, Closs SJ. The association between patient-professional partnerships and self-management of chronic back pain: a mixed methods study. Eur J Pain. 2018;22(7):1229-1244. doi:10.1002/ejp.1210

108. Johal H, Vannabouathong C, Chang Y, Zhu M, Bhandari M. Medical cannabis for orthopaedic patients with chronic musculoskeletal pain: does evidence support its use? Ther Adv Musculoskelet Dis. 2020;12:1759720X20937968. doi:10.1177/1759720X20937968

Journal of Pain Research

Dovepress

\section{Publish your work in this journal}

The Journal of Pain Research is an international, peer reviewed, open access, online journal that welcomes laboratory and clinical findings in the fields of pain research and the prevention and management of pain. Original research, reviews, symposium reports, hypothesis formation and commentaries are all considered for publication. The manuscript management system is completely online and includes a very quick and fair peer-review system, which is all easy to use. Visit http://www.dovepress.com/testimonials.php to read real quotes from published authors.

Submit your manuscript here: https://www.dovepress.com/journal-of-pain-research-journal 